\title{
Right Atrial Lipoma in a Patient With Complete Heart Block
}

\author{
Carlos D. Davila ${ }^{\mathrm{a}, \mathrm{d}}$, Leandro Slipczuk ${ }^{\mathrm{b}}$, Gregg S. Pressman ${ }^{\mathrm{c}}$
}

\begin{abstract}
A 70-year-old man with a recent history of high degree AV block presented to the hospital with progressive shortness of breath and dyspnea of exertion. A mobile intracardiac mass was found on transthoracic echocardiogram that was not present in his previous evaluations. Real time three-dimensional (3D) transesophageal echocardiography (TEE) images revealed a spherical mass within the right atrium; no enhancement after microbubble contrast infusion was noted. Modern echocardiography including 3D TEE and echocardiographic contrast perfusion imaging provide numerous advantages for non-invasive evaluation of intracardiac masses.
\end{abstract}

Keywords: Cardiac tumors; Lipoma; Echocardiography

\section{Introduction}

Primary neoplasm of the heart are extremely rare, especially intracavitary lipomas. The case we presented would broad the knowledge on non-invasive appreciation of cardiac lipomas and its potential association with conduction abnormalities.

\footnotetext{
Manuscript accepted for publication March 11, 2014

${ }^{\mathrm{a}}$ Department of Medicine, Einstein Medical Center, Philadelphia, Pennsylvania, USA

${ }^{b}$ Heart Institute, Cedars-Sinai Medical Center, Los Angeles, California, USA

${ }^{\mathrm{c}}$ Einstein Institute for Heart and Vascular Health, Einstein Medical Center, Philadelphia, Pennsylvania, USA

${ }^{\mathrm{d}}$ Corresponding author: Carlos D. Davila, Department of Medicine, Einstein Medical Center, Einstein Institute of Heart \& Vascular Health, 5501 Old York Road, Philadelphia, PA 19141, USA.

Email: Davilacc@einstein.edu
}

doi: http://dx.doi.org/10.14740/jmc1746w

\section{Case Report}

A 70-year-old man was admitted to the telemetry unit for shortness of breath. He had recently developed third degree AV block for which a dual-chamber pacemaker was implanted. No echocardiogram was performed prior to placement of the device. Physical exam was remarkable for evidence of COPD, but there was no evidence of decompensated heart failure. EKG showed normal function of the pacemaker. A transthoracic 2D echocardiogram (Philips iE33 xMATRIX Philips Electronics, MA, USA) unexpectedly revealed a large mobile, spherical echodensity measuring $2.5 \mathrm{~cm}$ in diameter in the right atrium (Fig. 1). The mass was further evaluated by transesophageal echocardiogram (TEE) including real time three-dimensional (3D) transesophageal echocardiography. It was found to be attached to the right atrial wall at the insertion of the superior vena cava and measured $2.7 \times 4.3 \mathrm{~cm}$ (Fig. 2A, B). Injection of perflutren lipid microsphere contrast (Definity ${ }^{\circledR}$ ) showed no enhancement by the mass, indicating an avascular structure. Device wires were not seen to be involved with the mass. Given the unclear etiology, the patient underwent surgical excision via a "mini" right anterior thoracotomy. Intraoperatively, the mass was identified and excised along with a portion of the atrial septum (Fig. 3A, B). A post-surgical TEE showed no atrial

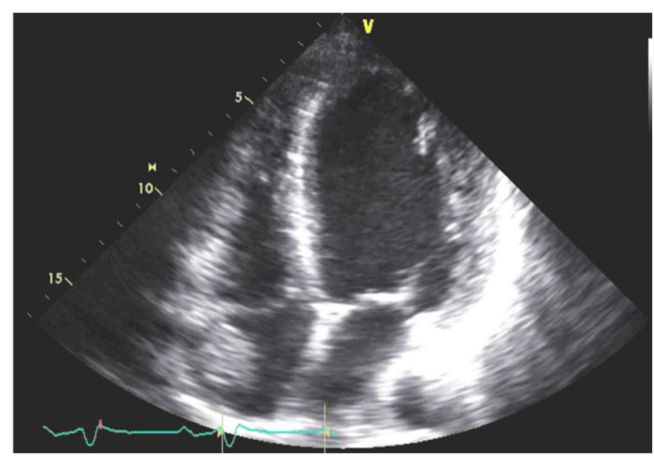

Figure 1. Transthoracic apical four chamber view. A large freely mobile echodense sphere is observed within the right atrium. 


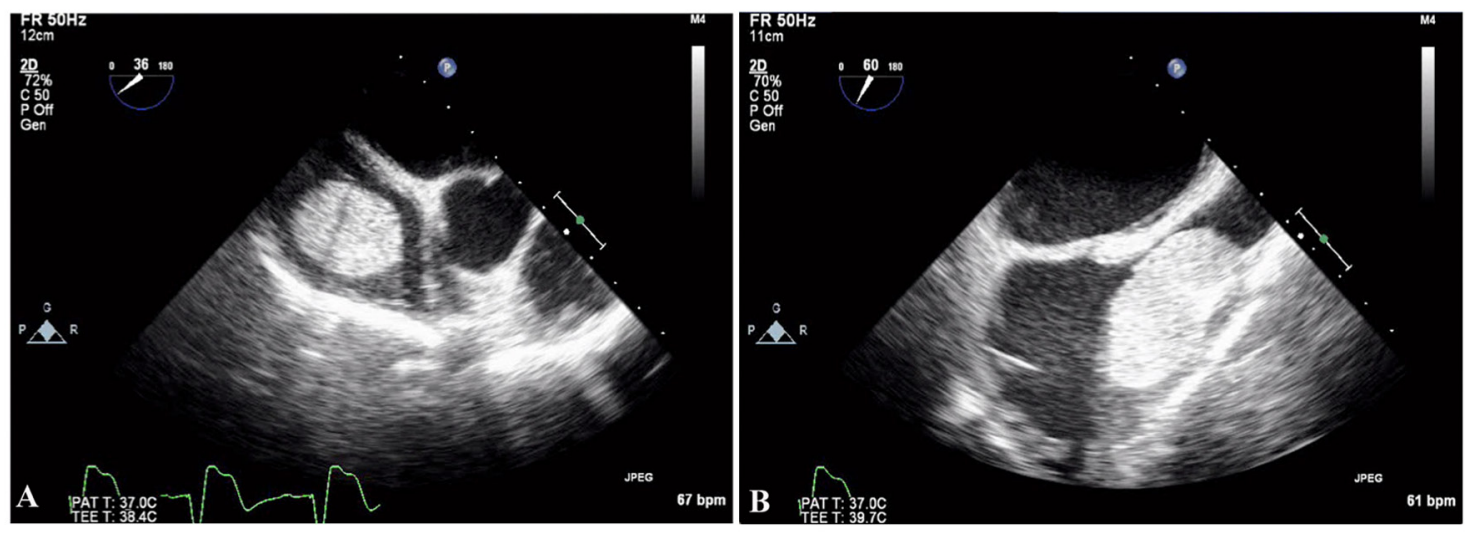

Figure 2. (A) Transesophageal echocardiography in a $30^{\circ}$ view shows a well demarcated mass within the right atrium. (B) Transesophageal echocardiography in a $60^{\circ}$ view shows the mass attached to the right atrium by a stalk close to the superior vena cava insertion site. Device wires are also seen.

septal defect and unchanged ventricular function. Pathology was consistent with a lipoma.

\section{Discussion}

Primary cardiac tumors are rare yet can cause significant arrhythmias, conduction abnormalities, embolism and blood flow obstruction [1]. Three quarters of primary cardiac tumors are benign in nature. Lipomas represent less than $5 \%$ of all cardiac tumors, and are usually located in the right atrium where they originate from either the atrial septum or atrial roof [2]. Although there is a direct relationship between size and clinical symptoms, cardiac lipomas are usually asymptomatic and may be discovered during routine evaluation such as in this case. Differential diagnosis may include iatrogenic device-related hematomas, other primary neoplasm of the heart or metastatic disease. Surgery may be indicated based on symptoms and etiology [3].
Echocardiography is the preferred study modality for non-invasive evaluation of intracardiac masses. Nevertheless, it cannot definitively establish etiology. During routine evaluation it is crucial to gather information about size, shape and attachment. The advantage of contrast perfusion imaging includes the potential characterization of vascularity in cardiac masses typically seen in malignant or vascular tumors. Conversely lack of vascular enhancement has been associated with other intracardiac masses, such as thrombus and benign tumors [4]. Additionally, real time 3D echocardiography allows rotation, cropping, volume assessment, slicing and superior spatial assessment of cardiac and surrounding structures that can add important information during evaluation of intracardiac masses.

\section{Acknowledgement}

Dr. Mark Anderson and Dr. Alessandro Bombonati.
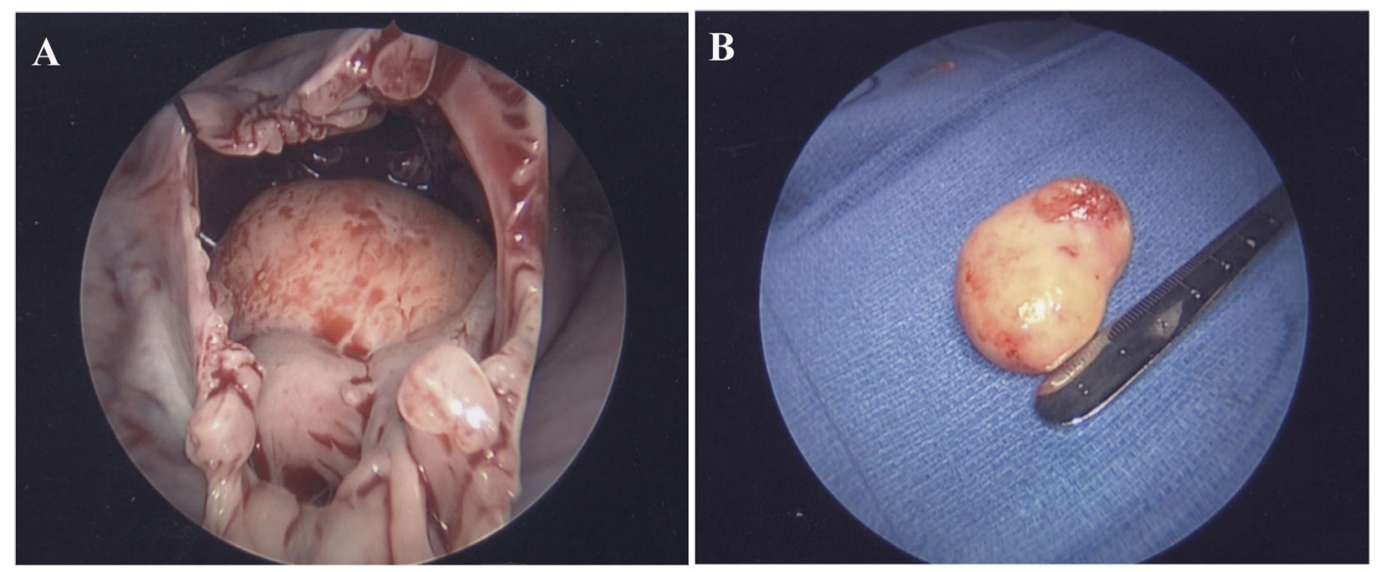

Figure 3. (A) Right anterior thoracotomy. (B) Intracardiac mass after resection. 


\section{Conflict of Interest}

None.

\section{Grant Support}

None.

\section{References}

1. Cina SJ, Smialek JE, Burke AP, Virmani R, Hutchins GM. Primary cardiac tumors causing sudden death: a review of the literature. Am J Forensic Med Pathol.
1996;17(4):271-281.

2. Reece IJ, Cooley DA, Frazier OH, Hallman GL, Powers PL, Montero CG. Cardiac tumors. Clinical spectrum and prognosis of lesions other than classical benign myxoma in 20 patients. J Thorac Cardiovasc Surg. 1984;88(3):439-446.

3. Kucukarslan N, Kirilmaz A, Ulusoy E, Baysan O, Yildirim V, Ozal E, Sahin MA, et al. Eleven-year experience in diagnosis and surgical therapy of right atrial masses. $\mathrm{J}$ Card Surg. 2007;22(1):39-42.

4. Kirkpatrick JN, Wong T, Bednarz JE, Spencer KT, Sugeng L, Ward RP, DeCara JM, et al. Differential diagnosis of cardiac masses using contrast echocardiographic perfusion imaging. J Am Coll Cardiol. 2004;43(8):14121419. 